\title{
PENGEMBANGAN KURIKULUM PENDIDIKAN \\ GURU MADRASAH IBTIDAIYAH TERINTEGRASI KEISLAMAN, \\ SAINS TEKNOLOGI, DAN KEARIFAN LOKAL DI INSTITUT AGAMA ISLAM NEGERI (IAIN) PALOPO
}

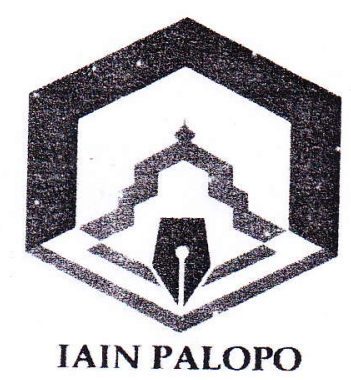

LAPORAN HASIL PENELITIAN

OLEH :

Dr. Edhy Rustan, M.Pd.

INSTITUT AGAMA ISLAM NEGERI (IAIN) PALOPO 2018 


\section{ABSTRAK}

Nama Penulis : Dr. Edhy Rustan, M.Pd.

NIDN : 9900987539

Judul : Pengembangan Kurikulum Pendidikan Guru Madrasah Ibtidaiyah Terintegrasi Keislaman, Sains Teknologi,dan Kearifan Lokal di Institut Agama Islam Negeri (IAIN) Palopo

Lulusan PGMI perlu memiliki kompetensi andal dengan berlandaskan kearifan lokal yang cakapperkembangan teknologi. Maka dari itu,pengembangan kurikulum KKNI yang terintegrasi keislaman, sains teknologi, dan kearifan lokal dilakukan guna menghasilkan struktur kurikulum yang mampu menjawab tantangan masa depan.

Penelitian ini adalah penelitian pengembangan (Research and Development) kurikulum dengan pendekatanmix method. Model ini termodifikasi menjadi 4 tahap yaitu (1) Studi pendahuluan dan Mengkaji Kebutuhan; (2) Tahap Rekonstruksi; dan (3) Tahap implementasi dan monitoring kurikulum, dan (4) Tahapan pengembangan draft dilakukan dengan panduan validitas expert oleh validitas ahli.

Berdasarkan perkembangan IPTEK, hasil analisis SWOT dan tracer study dengan melibatkan pemangku kepentingan, maka kurikulum PGMI dipandang perlu untuk diintegrasikan dengan keagamaan, kearifan lokal,dan perkembangan teknologi. Profil lulusan yang dirumuskan mencakup guru kelas, peneliti, desainer media, dan pembelajaran tingkat dasar. Struktur kurikulum yang mencakup rumpun matakuliah keagamaan, saintek, karakter, keguruan, serta muatan lokal dan pembinaan keterampilan.

Hasil uji coba kurikulum menunjukkan aspek yang ditinjau dosen, yakni: konten, sajian, manfaat, dan peluang implementasi model. Skor yang diperoleh dari ahli terhadap semua aspek yang diamati dengan kategori sangat baik.Kelayakan yang diperoleh dari respons mahasiswa terhadap perangkat model meliputi aspek pembelajaran, aspek isi, dan aspek tampilan dengan hasil praktis.Kelayakan pada uji coba kelompok kecil, diperoleh aktivitas mahasiswa melalui penerapan kurikulum berada pada iergolong efektif. Kelayakan model yang diperoleh dari hasil angket respons mahasiswa pada uji kelompok besar dengan fokus motivasi yang meliputi perhatian, relevansi, percaya diri, dan kepuasan mencapai kualifikasi sangat tinggi.Hasil yang diperoleh berdasarkan Focus Group Discussiondengan dosen dan pengamat mengacu pada indikator keterlaksanaan, diperoleh informasi bahwa model kurikulum ini sesuai dengan harapan.

Kata kunci: kurikulum, PGMI, keislaman, saintek, kearifan lokal 


\section{DAFTAR ISI}

HALAMAN JUDUL

HALAMAN SAMPUL

ABSTRAK

PRAKATA iv

SAMBUTAN KETUA LP2M v

SAMBUTAN PEJABAT PEMBUAT KOMITMEN vi

SURAT PERNYATAAN vii

DAFTAR ISI viii

DAFTAR BAGAN $\mathrm{X}$

DAFTAR TABEL —

DAFTAR GAMBAR $\quad$ xii

BAB I PENDAHULÜAN

A. LatarBelakang 1

B.RumusanMasalah 4

C. PenelitianRelevan 4

BAB 11 KAJIANPUSTAKA 6

A. Pengembangan Kurikulum 6

B. Model Pengembangan Kurikulum $\quad 8$

C. Konsep Kurikulum yang Kembangkan 13

D. Model Prosedural PengembanganKurikulum

BAB III TUJUAN DAN MANFAAT PENELITIAN 31

A. Tujuan Pengembangan 31

B. Kegunaan Hasil Penelition 31

BAB IV METODE PENGEMBANGAN 32

A. Prosedur Pengembangan $\quad 32$

B. Lokasi Penelitian 32 


\section{BAB I \\ PENDAHULUAN}

\section{A. Latar Belakang}

Pendidikansebagai salah satu sektor yang sangat penting dalam peningkatan sumber daya manusia yang berkualitas. Pendidikan berperan dalam pengembangan kemampuan, peningkatan mutu dan martabat manusia serta mewujudkan manusia yang terampil, potensial, dan berkualitas dalam melaksanakan pembangunan demi terwujudnya pembangunan nasional.

Pendidikan tidak hanya terbatas pada pengembangan intelektual, akan tetapi ditekankan pada pembiriaan kepribadian/ akhlak peserta didik hingga mampu tumbuh dewasa dalam konteks kehidupan pribadi maupun bermasyarakat. Oleh karena itu, proses pendidikan membutuhkan sumber daya manusia yang handal yang tidak hanya sekedar mengajar tetapi juga mendidik. Hal ini dikarenakan perilaku dan parangai seorang guru adalah cermin pembelajaran bagi peserta didik. Sebagaiman tokoh pendidikan Indonesia Ki Hajar Dewantara mengatakan bahwa guru selayaknya berprinsip "ing ngarso sung tulodo, ing madyo mangun karso, tut wuri handayani" (didepan memberi contoh, ditengah memberikan bimbingan dan dibelakang memberikan dorongan).

Berbagai Tantangan masa depan yang pelu dihadapi, mulai dari Globalisasi antara lain WTO, ASEAN Community, APEC, CAFTA, masalah lingkungan hidup, kemajuan teknologi informasi, konvergensi ilmu dan teknologi, ekonomi berbasis pengetahuan, kebangkitan industri kreatif dan budaya, pergeseran kekuatan ekonomi dunia, pengaruh dan imbas teknosains, Mutu, investasi dan transformasi pada sektor pendidikan serta karya berbasis inovasi menuntun pemerintah bahkan seluruh lapisan masyarakat untuk terus mengembankan pendidikan.Peningkatan mutu pendidikan merupakan prioritas utama dalam penyelenggaraan pendidikan.

Pemerintah melalui Kementerian Pendidikan Nasional telah berupaya meningkatkan mutu pendidikan melalui penyelenggaraan pendidikan yang berkualitas, seperti penyempurnaan kurikulum, pengadaan fasilitas belajar di sekolah dan memperbaiki sistem pembelajaran di kelas. Pemerintah pusat juga melakukan usaha untuk mendukung upaya dalam meningkatkan mutu pendidikan, diantaranya melakukan perbaikan sistem pendidikan di daerah, penyempurnaan kurikulum, peningkatan profesionalisme guru, pengadaan buku mata pelajaran, perbaikan sarana dan prasarana serta peningkatan 
penting dalam as. Pendidikan atan mutu dan mpil, potensial, mi terwujudnya

gan intelektual, akhlak peserta hidupan pribadi es pendidikan ng tidak hanya can perilaku dan gi peserta didik. jar Dewantara irso sung tulodo, nemberi contoh, memberikan

dapi, mulai dari CAFT'A, masalah rgensi ilmu dan industri kreatif aruh dan imbas stor pendidikan bahkan seluruh kan.Peningkatan enyelenggaraan

Nasional telah enyelenggaraan an kurikulum, perbaiki sistem an usaha untuk can, diantaranya penyempurnaan aan buku mata peningkatan kemampuan mengajar guru dengan menerapkan variasi model-model pembelajaran yang menuntut siswa belajar lebih aktif.

Pendidikan mempunyai peran yang sangat strategis dalam meningkatkan kualitas sumber daya manusia dan menggapai cita-cita bangsa Indonesia dalam mewujudkan kesejahteraan umum dan mencerdaskan kehidupan bangsa. Pemerintah merumuskannya dalam Undang-Undang Republik Indonesia No 20 tahun 2003 tentang Sistem Pendidikan Nasional yang menjelaskan bahwa pendidikan dilakukan agar mendapatkan tujuan yang diharapkan bersama yaitu untuk berkembangnya potensi peserta didik agar menjadi manusia yang beriman dan bertakwa kepada Tuhan Yang Maha Esa, berakhlak mulia, sehat, berilmu, cakap, kreatif, mandiri, dan menjadi warga negara yang demokratis serta bertanggung jawab. ${ }^{1}$

Peningkatan mutu pendidikan tidak terlepas dari adanya kurikulum. Kurikulum sebagai suatu rancangan pendidikan yang memiliki posisi sangat strategis, karena seluruh kegiatan pendidikan bermuara pada kurikulum. Di samping itu, kurikulum juga merupakan deskripsi dari visi, misi dan tujuan pendidikan bangsa sehingga penyusnannya memerlukan landasan dan pondasi yang kuat, melalui pemikiran dan penelitian yang mendalam.

Berdasarkan hasil pengamatan, masalah kurikulum Pendidikan Guru Madrasah Ibtidaiyah (PGMI) IAIN Palopo tidak menjabarkan visi, misi, serta tujuan institusi yang berorientasi pada keislaman, sains teknologi serta kearifan lokal. Selain itu, penempatan mata kuliah yang tidak berimbang dan terstruktur di setiap semester. Struktur kurikulum PGMI juga tidak mewakili seluruh aspek bidang studi, dimana terlihat rancangan kurikulum untuk mata kuliah program studi mengalami ketimpangan. Tidak menjangkaunya segala aspek mata pelajaran yang tersedia menyebabkan menurunnya kualitas dari mahasiswa. Selain itu, dengan perkembangan ilmu pengetahuan dan teknologi juga mempengaruhi kurikulum sehingga perlu adanya penyesuaian. Kurikulum yang harus dikembangkan ialah kurikulum yang berbasis teknologi.

Laporan tracer study juga memberikan gambaran di lapangan bahwa mahasiswa perlu memiliki kemampuan diantaranya penguasan bahasa asing, penguasaan IT, keterampilan penunjang pendidikan serta perlunya kualitas penelitian pembelajaran.

Berkenan dengan fenomena tersebut, perlu adanya pembaharuan pada rancangan ini dimana kurikulum madrasah ibtidaiyah yang ada

${ }^{1}$ Undang - undang Republik Indonesia No. 20 tahun 2003, Sistem Pendidikan Nasional, (Bandung: Citra Umbara, 2003), h. 5 
lai-nilai makna

alum haruslah fleskibel dan asan yang kuat mendasar yang p-konsep yang

enuntut dunia us berkembang angsa. Keadaan ngikis bahkan n-temurun. Pola darnya kearifan

anak sejak dini budaya pada imnya muatan ghilangkan nilai rmasalahan ini, serta menggali pada anak sejak ggsa. Selain itu, asilkan manusia berakhiak mulia me guru dituntut m menghadapi mbelajaran yang meraih tujuan

ikulum karena nsekuensi pada adaptasi dengan ntuk melakukan endidikan Guru ns Teknologi, dan alopo.

\section{B. Rumusan Masalah}

Berdasarkan latar belakang di atas, maka rumusan masalah dalam penelitian inisebagai berikut:

1. Bagaimana kebutuhankurikulum pendidikan guru madrasah ibtidaiyah di IAIN Palopo?

2. Bagaimana ancangan kurikulum pendidikan guru madrasah ibtidaiyah yang terintegrasi keislaman, sains teknologi, dan kearifan lokal di IAIN Palopo?

3. Bagaimana desain kurikulum pendidikan guru madrasah ibtidaiyah yang terintegrasi keislaman, sains teknologi, dan kearifan lokal di IAIN Palopo berdasarkan pandangan ahli?

4. Bagaimana penerapan kurikulum PGMI yang terintegrasi keislaman, sains teknologi dan kearifan lokal di IAIN Palopo?

5. Efektivitas kurikulum PGMI yang terintegrasi keislaman, sains teknologi dan kearifan lokal di IAIN Palopo?

\section{Penelitan Relevan}

Penelitian ini mengkaji dan menelaah beberapa hasil penelitian terdahulu yang terkait dengan variabel dalam penelitian ini. Hal ini dijadikan sebagai pandangan awal agar peneliti mengetahui peranan penting kurikulum dalam dunia pendidikan dan menghadapi tantangan masa depan. SebagaimanaMuhamad Tisna Nugraha ${ }^{2}$ dengan judul Pengembangan Modei Kurikulum Pendidikan Agama Islam (PAI) Menuju Masyarakat Ekonomi Asean (MEA). Penelitian ini dilakukan pada tahun 2016 dengan hasil penelitian bahwa kurikulum PAl di lembaga pendidikan Islam, saat ini sedang menghadapi berbagai tantangan di dalam menghadapi masyarakat eknomi ASEAN (MEA). Untuk itu, para pemangku kebijakan pendidikan (policy maker) dipandang perlu melakukan upaya perbaikan, penyesuaian (relevansi) terutama di dalam meningkatkan kualitas dan keahlian lulusan lembaga pendidikan Islam agar dapat langsung dipakai di pasar kerja. Adapun pengembangan kurikulum PAI yang dapat dilakukan saat ini adalah dengan memperbaharui dan memodifikasi kurikulum yang sudah ada. Termasuk memberikan peluang membentuk kurikulum terpadu antara lembaga pendidikan Islam se-Asia tenggara serta pengembangan kompetensi lintas kurikulum se-Asia tenggara, dengan demikian, apa yang menjadi kebutuhan dan peluang dunia kerja, khususnya sektor pendidikan agama dapat diraih secara tepat sasaran. Selain itu, hal lain yang tidak kalah penting adalah pembekalan kemampuan penguasaan bahasa April 2017.

${ }^{2}$ jurnaliainpontianak.or.id/index.php/atturats/article/download/447/pdf Diakses 28 
kegiatan belajar guasaan bahasa erta membantu si antar lintas

\section{BAB II \\ TINJAUAN PUSTAKA}

\section{A. Pengembangan Kurikulum}

Secara etismologi, kurikulum berasal dari bahasa Yunani, yaitu curir yang artinya pelari, dan curare yang berarti tempat berpacu. Jadi istilah kurikulum berasal dari dunia olahraga pada zaman Romawi Kuno di Yunani, yang berarti jarak yang harus ditempuholeh pelari dari garis start sampai finish. ${ }^{3}$ Seperti yang diketahui, jarak yang harus ditempuh disini bermakna kurikulum dengan muatan isi dan materi pelajaran yang dijadikan jangka waktu yang harus ditempuh oleh peserta didik untuk meraih gelar maupun ijazah. Dalam bahasa arab, kata manhaj mewakili kata untuk kurikulum yang berartijalan terang yang dilalui manusia pada berbagai bidang kehidupan. Sedangkan kurikulum pendidikan (manhaj al-dirasah) dalam kamus tarbiyah adalah seperangkat perencanaan dan media yang dijadikan acuan oleh lembaga pendidikan dalam meujudkan tujuan-tujuan pendidikan. ${ }^{4}$

Menurut S Nasution, kurikulum merupakan suatu proses rencana yang disusun untuk melancarkan proses belajar mengajar dibawah bimbingan dan tanggung jawab sekolah atau lembaga pendidikan beserta staf pengajaran. Selanjutnya Nasution menjelaskan sejumlah ahli teori kurikulum berpendapat bahwa kurikulum bukan hanyameliputi semua kegiatan yang direncanakan melainkan peristiwa-peristiwa yang terjadi dibawah pengawasan sekolah. Jadi selain kegiatan kurikulum formal yang sering disebut ko-kurikuler atau ekstra kurikuler. ${ }^{5}$

Sejalan dengan defenisi diatas, Dakir mengungkapkan bahwa kurikulum adalah suatu program pendidikan yang berisikan berbagai bahan ajar dan pengalaman belajar yang diprogramkan, direncanakan dan dirancangkan secara sistemik atas dasar norma-norma yang berlaku yang dijadikan pedoman dalam proses pembelajaran bagi tenaga kependidikan dan peserta didik untuk mencapai tujuan pendidikan. ${ }^{6}$ Sedangikan, dalam Undang-Undang Sistem Pendidikan Nasional Tahun 1989 Bab I pasal 1 disebutkan bahwa: "Kurikulum adalah seperangkat rencana dan peraturan mengenai isi dan bahan pelajaran serta cara yang digunakan sebagai pedoman penyelenggara

\footnotetext{
${ }^{3}$ Hasan Langgulung, Mamusia dan Pendidikan Suatu Analisa Psikologi Pendidikan. (Jakarta: Pustaka Al-Husna, 1986), h. 176.

${ }^{4}$ Op.Cit., h.176.

5 S. Nasution, Kurikulum dan Pengajaran, (Jakarta : Rineka Cipta, 1989), h.5.

${ }^{6}$ Dakir, Perencanaan dan Pengembangan Kurikulum, (Jakarta: Rineka Cipta, 2004), h. 3 .
} 
cas, maka dapat peratutan yang

ng terkait satu bangan. Hal ini ada dasarnya m sekarang ke bagai pengaruh dalam sendiri, asa depan yang ersifat ansipatif,

kurikulum link perlukan. Untuk dah. Salah satu ip-prinsip yang ditentukan oleh

ru-guru (aspek

1a, kebudayaan pagainya)(Aspek

fisik, mental, belajar (aspek

aran). ${ }^{7}$

di atas, dalam tiga pendekatan

emilihan materi. pengembangan nya menuju ke i berikut:

Rineka Cipta, 2004), d) Cara pengorganisasian bahan pelajaran,

e) Buku sumber yang relevan,

f) Media pembelajaran,

g) Tujuan pendidikan.

2. Pendekatan berdasarkan tujuan

Peyusunan kurikulum dengan pendekatan berdasarkan tujuan, artinya mencantumkan tujuan pendidikan di Indonesia terlebih dahulu sesuai yang tertera pada GBHN. Dari tujuan inilah dijabarkan menjadi tujuan-tujuan yang lebih terinci, yang akhirnya ke tujuan yang bersifat operasional.

3. Pendekatan berdasarkan kemampuan

Pada pendekatan ini pada dasarnya sama dengan penyusunan kurikulum berdasarkan tujuan. Pada pendektakan ini tujuannya lebih operasional. Diibaratkan bahwa kemampuan yang akan dicapai merupakan tujuan institusional, sedangkan tujuan kurikulum yaitu berupa berbagai sub kemampuan yang masingmasing berorientasi pada profesi.

\section{B. Model Pengembangan Kurikulum}

Dalam pengembangan kurikulum, para pengembang kurikulum dapat memulai dengan memilih model konsep pengembangan yang ditawarkan oleh para ahli kurikulum. Model adalah konstruksi yang bersifat teoritis dari konsep. ${ }^{9}$ Pemilihan model ini dilakukan denganmempertimbangkan aspek lokalitas atau kebutuahan masyarakat di mana institusi itu berada. Beberapa model pengembangan berikut ini dapat dipilih oleh para pengembang kurikulum dengan mempertimbangkan hubungan antara elemen kurikulum dan urutan penyusunannya sebagai berikut :

a. Model Ralph Tyler.

Model pengembangan Tyler tidak menyebutkan langkah-langkah konkret dalam pengembangan kurikulum. Menurut Tyler kurikulum harus disusunsecara logis dan sistematis. Untuk menyusun kurikulum ada empat pertanyaanmendasar yang harus diajukan :

1) Apa tujuan pendidikan yang ingin dicapai?

2) Apa pengalaman pendidikan yang dibutuhkan untuk mencapai tujuan?

3) Bagaimana mengorganisasikan pengalaman belajar secara efektif? Dan

\footnotetext{
${ }^{9}$ Op.cit., h. 95.
} 


\section{BAB VII \\ KESIMPULAN DAN SARAN}

\section{A. Kesimpulan}

Berdasarkan hasil analisis dan pembahasan, hasil penelitian pengembangan kurikulum dapat disimpulkan bahwa hasil analisis kondisi objektif Program Studi PGMI dimana diperoleh bahwa perlu adanya perubahan kurikulum. Hal ini terihat dari perkembangan program studi PGMI dari tahun ke tahun baik dari segi mahasiswa, dosen, sarana dan prasarana.

Ancangan kurikulum PGMI disusun dan dintegrasikan dengan visi misi prodi, fakultas dan institusi yang terintegrasi keislaman, sains teknologi, dan kearifan local. Selain itu, desain kurikulum PGMI yang terintegrasi keislaman, sains teknologi, dan kearifan lokal sesuai dengan perkembangan yang terjadi di masyarakat. Pengembangan kurikulum melibatkan pemangku kepentingan, baik program studi maupun unsur yang yang terlibat dalam pengelolaan.

Focus Group Discussiondengan dosen dan pengamat mengacu pada indikator keterlaksanaan, diperoleh informasi bahwa model kurikulum ini sesuai dengan harapan. Model yang dihasilkan dapat dijadikan penunjang pelaksanaan kurikulum pergurun tinggi.

\section{B. Saran}

Berdasarkan hasil-hasil dan temuan-temuan yang diperoleh dalam penelitian pengembangan ini, 
maka dikemukakan beberapa saran atau rekomendasi sebagai berikut.

1. Disarankan kepada program studi agar memperhatikan dan menyesuaikan kurikulum sesuai dengan perkembangan zaman. Hal ini dibutuhkan mahasiswa mampu bersaing ditengah-tengah perkembangan global.Selain itu, perlu diadakannya evaluasi atas komponen kurikulum yang dirancang.

2. Kepada pakar dan peneliti di bidang pendidikan diharapkan untuk melakukan penelitian serupa pada masa mendatang, baik dengan tujuan meningkatkan kualitas lulusan. 


\section{DAFTAR PUSTAKA}

Anwar, Idwar. (2007)Ensiklopedi Kebudayaan Luwu. Komunitas Kampung Sawerigading (KAMPUS). Pemerintah Kota Palopo. Pemerintah Kabupaten Luwu Utara. Pemerintah Kabupaten Luwu Timur. PT INCO : Pustaka Sawerigading.

Arifin, Zainal. (2011). Konsep dan Model Pengembangan Kurikulum. Bandung: PT.Remaja Rosdakarya.

Asep \& Herry Hernawan. (2014). Hakikat Kurikulum Dan Pembelajaran," in Modul Pembelajaran.

AUN-QA. (2015). Guide to AUN-QA Assessment at Programme Level Version 3.0. Bangkok: ASEAN University Network.

Baiquni, Achmad. (1995).Al-Qur'an, Ilmu Pengetahuan dan Teknologi, Yogyakarta: Dana Bhakti Wakaf.

Bin, J. O.Living Better. (AUN-QA Network) Retrieved 2016 Maret, 2016, from http://livingbetterforhappiness.blogspot.co.id/20 15/12/the-tenprinciples-behind-aur-qamodel.html

Dakir. (2004).Perencanaan dan Pengembangan Kurikulum, Jakarta: Rineka Cipta.

Hasan, Hamid S. (2008). Evaluasi Kurikulum. Bandung: PT. Remaja Rosdakrya. 